Article

\title{
Extraction of Gold(III) from Hydrochloric Acid Solutions with a PVC-based Polymer Inclusion Membrane (PIM) Containing Cyphos $^{\circledR}$ IL 104
}

\author{
Ya Ya Nutchapurida Bonggotgetsakul, Robert W. Cattrall and Spas D. Kolev * \\ School of Chemistry, The University of Melbourne, Victoria 3010, Australia; \\ E-Mails: yayabong88@gmail.com (Y.Y.N.B.); r.cattrall@unimelb.edu.au (R.W.C.) \\ * Author to whom correspondence should be addressed; E-Mail: s.kolev@unimelb.edu.au; \\ Tel.: +61-383-447-931; Fax: +61-393-475-180.
}

Academic Editor: Alexey Volkov

Received: 17 November 2015/ Accepted: 3 December 2015/ Published: 8 December 2015

\begin{abstract}
Poly(vinyl chloride) (PVC) based polymer inclusion membranes (PIMs), with different concentrations of Cyphos ${ }^{\circledR}$ IL 104 as the membrane extractant/carrier, were studied for their ability to extract $\mathrm{Au}(\mathrm{III})$ from hydrochloric acid solutions. Some of the PIMs also contained one of the following plasticizers or modifiers: 2-nitrophenyloctyl ether, dioctylphthalate, 1-dodecanol, 1-tetradecanol, or tri(2-ethylhexyl) phosphate. The best performance, in terms of extraction rate and amount of $\mathrm{Au}(\mathrm{III})$ extracted, was exhibited by a PIM consisting of $25 \mathrm{wt} \%$ Cyphos $^{\circledR}$ IL 104, $5 \mathrm{wt} \%$ 1-dodecanol, and $70 \mathrm{wt} \%$ PVC. An almost complete back-extraction of the Au(III) extracted from this membrane was achieved by using a $0.10 \mathrm{~mol} \mathrm{~L}^{-1} \mathrm{Na}_{2} \mathrm{SO}_{3}$ receiver solution at $\mathrm{pH} 8$. The stoichiometry of the extracted $\mathrm{Au}(\mathrm{III}) / \mathrm{Cyphos}{ }^{\circledR} \quad$ IL 104 adduct was determined as $[\mathrm{P}]^{+}\left[\mathrm{AuCl}_{4}\right]^{-} \mathrm{H}^{+}\left[\mathrm{PO}_{2}\right]^{-}$where $[\mathrm{P}]^{+}$and $\left[\mathrm{PO}_{2}\right]^{-}$represent trihexyl(tetradecyl) phosphonium and bis(2,4,4-trimethylpentyl) phosphinate ions, respectively. Back-extraction of Au(III) is suggested to occur by reduction of $\mathrm{Au}(\mathrm{III})$ to $\mathrm{Au}(\mathrm{I})$, with the formation of the species $\left[\mathrm{Au}\left(\mathrm{SO}_{3}\right)_{2}\right]^{3-}$ in the aqueous receiver solution. Loss of 1-dodecanol from the newly developed PIM to the aqueous solutions in contact with it was observed, which indicated that this membrane was suitable for single use in the efficient recovery of $\mathrm{Au}(\mathrm{III})$ from hydrochloric acid solutions of electronic scrap or recycled jewelry.
\end{abstract}

Keywords: polymer inclusion membrane (PIM); extraction; Cyphos ${ }^{\circledR}$ IL 104; gold recovery 


\section{Introduction}

During the past decade, there have been a number of studies of gold recovery from acid solutions using polymer inclusion membranes (PIMs) [1-5]. It has been reported that PIMs offer advantages over traditional solvent extraction, as they mimic the latter's separation ability but without the use of a large inventory of diluents, which are often highly volatile and flammable liquids [6-8].

PIMs consist of an extractant (often referred to as carrier) and a base polymer (commonly poly(vinyl chloride) (PVC) or cellulose triacetate (CTA)). In some cases, they may also contain a plasticizer or modifier. The extractant is usually a liquid complexing agent or an ion-exchanger, responsible for binding with the target species and transporting it across the PIM; plasticizers improve the compatibility between the extractant and the base polymer, thus, making the membrane homogeneous and flexible, while modifiers enhance the solubility of the adduct of the extractant and the target species in the membrane liquid phase [7]. Several extractants have been used in $\mathrm{Au}$ (III) recovery from acidic solutions, such as Aliquat 336 [1,5], Kelex 100 [2], $\omega$-thiocaprolactam [4] (this PIM was used mainly for $\operatorname{Pd}($ II) separation), and thiacalix[4]arenes [3]. These studies have shown successful extraction of $\mathrm{Au}(\mathrm{III})$ from hydrochloric acid solutions, with good selectivity over other base metal ions. However, difficulties with efficient stripping of $\mathrm{Au}$ (III) from the proposed PIMs have been encountered, i.e., in the case of the Kelex 100-based PIM, stripping of up to $85 \%$ of Au(III) could be achieved [2], while up to $65 \%$ of $\mathrm{Au}$ (III) could be transported across a thiacalix[4]arene-based PIM [3]. Argiropoulos et al. [1] have reported on the high selectivity of a PIM composed of PVC and Aliquat 336 as the carrier for $\mathrm{Au}(\mathrm{III})$ extraction from hydrochloric acid solutions, even in the presence of a 500-fold higher concentration of $\mathrm{Cu}$ (II). However, they encountered difficulties in stripping $\mathrm{Au}(\mathrm{III})$ in the receiving solution during transport experiments, and observed some instabilities of the membrane.

Guo et al. [9] have reported on the successful use of a PIM incorporating the ionic liquid extractant Cyphos $^{\circledR}$ IL 104 as the extractant/carrier and polyvinylidene fluoride (PVDF) as the base polymer for $\mathrm{Cr}(\mathrm{VI})$ transport. The membrane showed a faster transport rate and a higher stability than that using Aliquat 336 as the carrier. The stripping of the target chemical species was easily achieved by using a $\mathrm{NaOH}$ solution. The present paper describes the use of a PVC-based PIM containing Cyphos ${ }^{\circledR}$ IL 104 as the carrier for the efficient extraction of $\mathrm{Au}(\mathrm{III})$ from hydrochloric acid solutions.

\section{Results and Discussion}

\subsection{Optimization of the Membrane Composition}

An initial study of the membrane composition with Cyphos ${ }^{\circledR}$ IL104 as the carrier and PVC as the base polymer was carried out by preparing membranes with the following compositions: Cyphos ${ }^{\circledR}$ IL $104(20-40 \mathrm{wt} \%)$ and PVC (60-80 wt \%) or with Cyphos ${ }^{\circledR}$ IL 104 (20 wt\%), PVC (70 wt\%) and $10 \mathrm{wt} \%$ of one of the following plasticizers or modifiers: 2-nitrophenyloctyl ether, dioctylphthalate, 1dodecanol, 1-tetradecanol, and tri(2-ethylhexyl) phosphate. It was observed that only PIMs prepared with the extractant alone, or with the addition of the modifier 1-dodecanol, were homogeneous, transparent, and flexible. The membranes containing the other plasticizers and modifiers had oily surfaces, which indicated incompatibility of their components. Therefore, membranes were prepared 
for further study with the compositions shown in Table 1, and the appearance of these PIMs was observed visually.

PIMs that were homogeneous, transparent, and flexible (listed in Table 1 as "clear") were tested for their ability to extract $\mathrm{Au}$ (III) from $2.5 \mathrm{~mol} \mathrm{~L}^{-1} \mathrm{HCl}$, and the results are shown in Figure 1, as the decrease in the $\mathrm{Au}(\mathrm{III})$ concentration in the aqueous phase with time. Figure 1 demonstrates a considerably higher extraction rate, and amount extracted for PIMs with 1-dodecanol as the modifier than for PIMs without it. The PIM composition containing $25 \mathrm{wt} \%$ Cyphos ${ }^{\circledR}$ IL 104, 5 wt \% 1dodecanol and $70 \mathrm{wt} \% \mathrm{PVC}$, corresponding to the highest extraction rate and amount of $\mathrm{Au}$ (III) extracted (Figure 1), was selected as the optimum PIM composition.

Table 1. Homogeneity of polymer inclusion membranes (PIMs) containing poly(vinyl chloride) (PVC), Cyphos ${ }^{\circledR}$ IL 104 and 1-dodecanol.

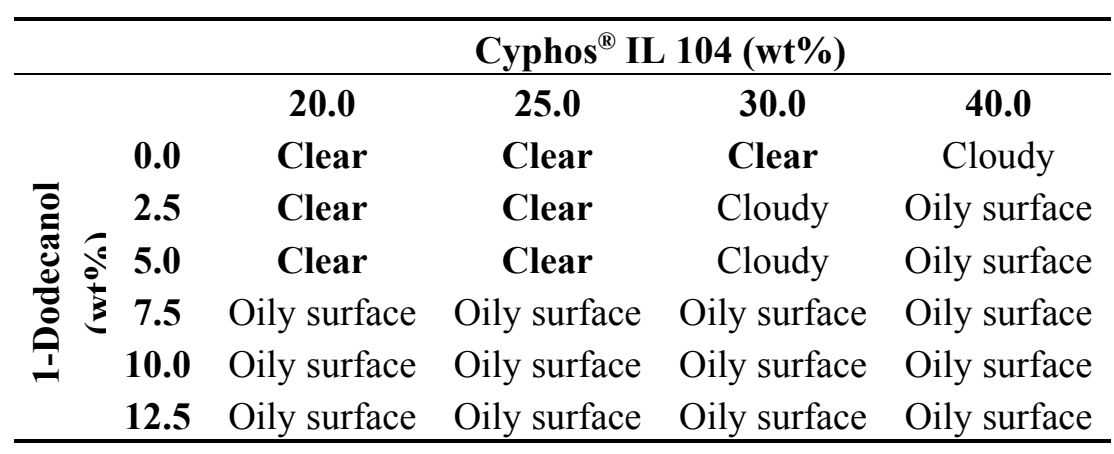

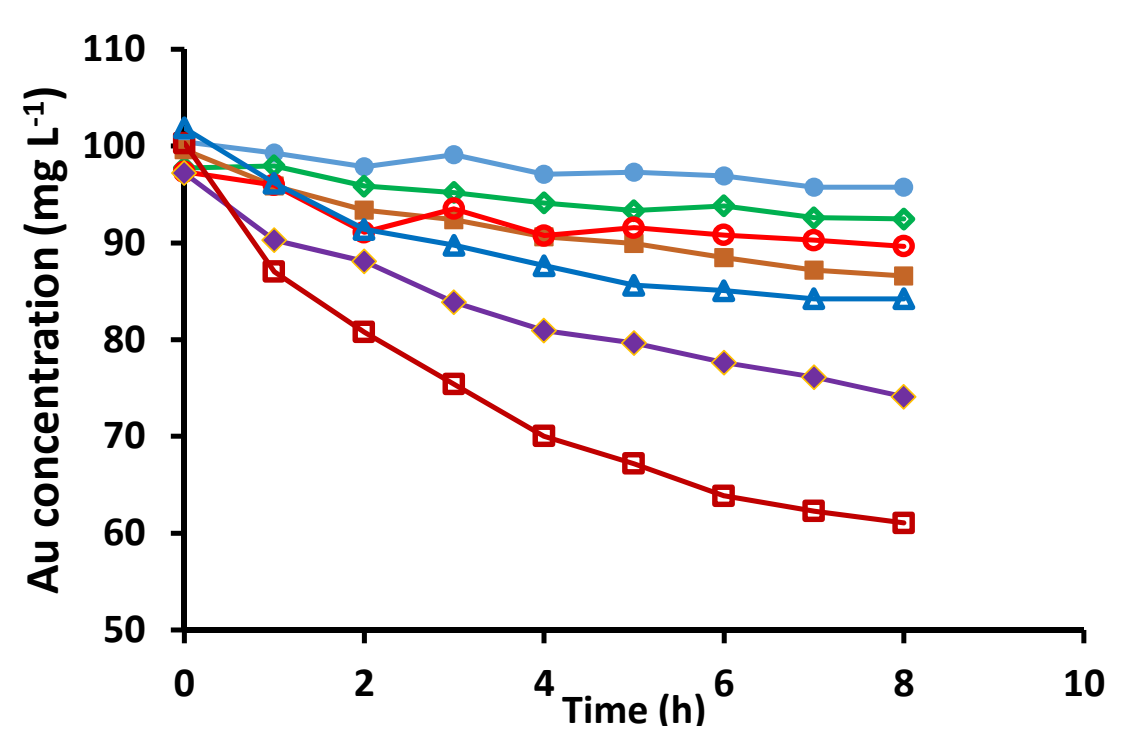

Figure 1. The extraction of $\mathrm{Au}(\mathrm{III})$ from $2.5 \mathrm{~mol} \mathrm{~L}^{-1} \mathrm{HCl}$ using the following PIMs containing PVC, 1-dodecanol and Cyphos ${ }^{\circledR}$ IL 104 (IL), and characterized as "clear" in Table 1: $20 \mathrm{wt} \% \mathrm{IL} ; \diamond 20 \mathrm{wt} \%$ IL and $2.4 \mathrm{wt} \%$ 1-dodecanol; $\square 20 \mathrm{wt} \%$ IL and $5 \mathrm{wt} \%$ 1-dodecanol; O $25 \mathrm{wt} \% \mathrm{IL} ; \quad 25 \mathrm{wt} \%$ IL and $2.5 \mathrm{wt} \%$ 1-dodecanol; $\square 25 \mathrm{wt} \% \mathrm{IL}$ and $5 \mathrm{wt} \%$ 1-dodecanol; and $\triangle 30 \mathrm{wt} \%$ IL (The remaining percentage in all PIMs is PVC). Aqueous phase: $100 \mathrm{~mL}, 100 \mathrm{mg} \mathrm{L}^{-1} \mathrm{Au}(\mathrm{III}), 2.5 \mathrm{~mol} \mathrm{~L}{ }^{-1} \mathrm{HCl}$; membrane mass and thickness: $60 \pm 3 \mathrm{mg}, 50 \pm 5 \mu \mathrm{m}$; shaking rate: $150 \mathrm{rpm}$. Data points are the average of 3 extraction experiments with an average standard deviation of $0.64 \mathrm{mg} \mathrm{L}^{-1}$. Membranes of similar masses and sizes were used. 


\subsection{Effect of the HCl Concentration}

The effect of the concentration of $\mathrm{HCl}$ in the range of $0.050-3.0 \mathrm{~mol} \mathrm{~L}^{-1}$ on $\mathrm{Au}(\mathrm{III})$ extraction was studied. The extraction results in Figure 2 show an increase in the $\mathrm{Au}(\mathrm{III})$ extraction rate and equilibrium $\mathrm{Au}(\mathrm{III})$ amount extracted, as the concentration of $\mathrm{HCl}$ is increased from $0.050 \mathrm{~mol} \mathrm{~L}^{-1}$ to $2.5 \mathrm{~mol} \mathrm{~L}^{-1}$. As shown in Section 2.3, the extraction mechanism involves the positively charged phosphonium group of Cyphos ${ }^{\circledR}$ IL 104, forming an ion-pair with the tetrachloroaurate(III) anion, which is accompanied by the formation of an ion-pair between the $\mathrm{H}^{+}$ion and the negatively charged phosphinate group. Therefore, an increase in the concentration of $\mathrm{HCl}$ should lead to an increase in the extraction rate and the amount of $\mathrm{Au}(\mathrm{III})$ extracted. This effect was observed for $\mathrm{HCl}$ concentrations lower than $2.5 \mathrm{~mol} \mathrm{~L}^{-1}$ but there was no improvement in the rate of $\mathrm{Au}(\mathrm{III})$ extraction and the amount extracted when the concentration of $\mathrm{HCl}$ was higher than this value. Hence, $2.5 \mathrm{~mol} \mathrm{~L}^{-1}$ was chosen as the optimum $\mathrm{HCl}$ concentration.

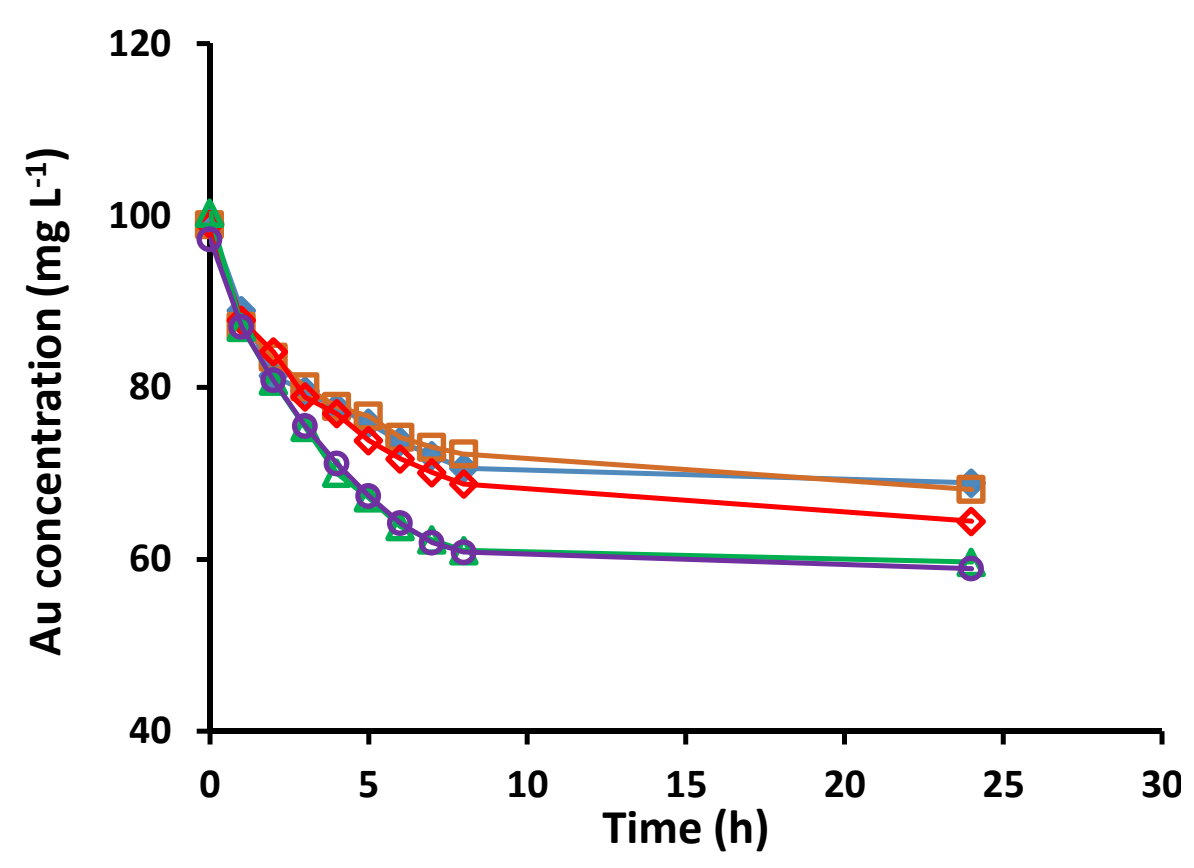

Figure 2. Extraction of $\mathrm{Au}(\mathrm{III})$ from aqueous solutions with different $\mathrm{HCl}$ concentrations $\left(\diamond 0.05, \square 0.10, \diamond 1.0, \triangle 2.5\right.$, and $\bigcirc 3.0 \mathrm{~mol} \mathrm{~L}^{-1}$ ) (Aqueous phase: $100 \mathrm{~mL}, 100 \mathrm{mg} \mathrm{L}{ }^{-1}$ $\mathrm{Au}(\mathrm{III})$; membrane mass and thickness: $60 \pm 3 \mathrm{mg}, 50 \pm 5 \mu \mathrm{m}$; membrane composition: $25 \mathrm{wt} \%$ Cyphos ${ }^{\circledR}$ IL 104, $5 \mathrm{wt} \%$ 1-dodecanol and $70 \mathrm{wt} \%$ PVC; shaking rate: $150 \mathrm{rpm}$ ). Data points are the average of 3 extraction experiments with an average standard deviation of $0.59 \mathrm{mg} \mathrm{L} \mathrm{L}^{-1}$. Membranes of similar masses and sizes were used.

\subsection{The $A u(I I I)$ Extraction Mechanism}

In order to elucidate the $\mathrm{Au}(\mathrm{III})$ extraction mechanism, it is important first to establish the stoichiometry of the extracted $\mathrm{Au}$ (III)-Cyphos ${ }^{\circledR}$ IL 104 adduct. This was carried out using a variation of the method described by St. John et al. [10]. This involved extracting $\mathrm{Au}(\mathrm{III})$ from $2.5 \mathrm{~mol} \mathrm{~L}{ }^{-1} \mathrm{HCl}$ using PIM segments of different masses (PIM composition, $25 \mathrm{wt}^{\%}$ Cyphos ${ }^{\circledR}$ IL 104, 5 wt\% 
1-dodecanol and $70 \mathrm{wt} \%$ PVC). The masses of the PIM segments were varied to achieve different mole ratios between the extractant in the PIM to the $\mathrm{Au}(\mathrm{III})$ in the solution.

The results are shown in Figure 3 as a plot of the mole ratio of $\mathrm{Au}(\mathrm{III})$ to $\mathrm{Cyphos}^{\circledR}$ IL 104 in the

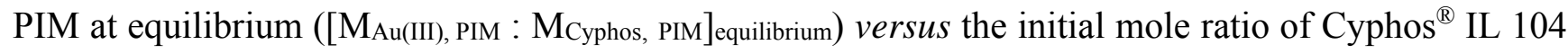

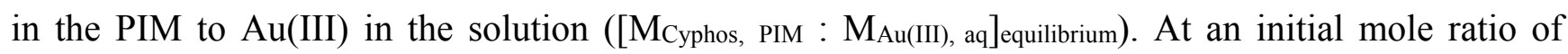
Cyphos $^{\circledR}$ IL 104 in the PIM to $\mathrm{Au}(\mathrm{III})$ in a solution of less than 1:1, the equilibrium mole ratio of $\mathrm{Au}$ (III) to Cyphos ${ }^{\circledR}$ IL 104 in the PIM is constant with a value of approximately 1:1. This corresponds to a "full loading" of the available Cyphos ${ }^{\circledR}$ IL 104 in the PIM. At mole ratios of Cyphos ${ }^{\circledR}$ IL 104 to $\mathrm{Au}(\mathrm{III})$ in the solution of greater than $1: 1$, there is insufficient $\mathrm{Au}(\mathrm{III})$ extracted to "fully load" Cyphos $^{\circledR}$ IL 104, and so the equilibrium mole ratio of $\mathrm{Au}$ (III) to Cyphos ${ }^{\circledR}$ IL 104 in the PIM decreases. This result suggests that the stoichiometry of the adduct formed in the PIM between Cyphos ${ }^{\circledR}$ IL 104 and $\mathrm{Au}(\mathrm{III})$ is $1: 1$, and, together with a decrease in the $\mathrm{pH}$ of the receiver phase during back-extraction (see Section 2.4, Equation (2)), supports an extraction mechanism described by Equation (1). The membrane loading capacity of the PVC-based PIM was determined in these experiments as $0.38 \mathrm{meq} \mathrm{g}^{-1}$.

$$
[\mathrm{P}]^{+}\left[\mathrm{PO}_{2}\right]_{(\mathrm{PIM})}^{-}+\mathrm{HAuCl}_{4(\mathrm{aq})} \rightarrow[\mathrm{P}]^{+}\left[\mathrm{AuCl}_{4}\right]^{-} \mathrm{H}^{+}\left[\mathrm{PO}_{2}\right]^{-}(\mathrm{PIM})
$$

where $[\mathrm{P}]^{+}$and $\left[\mathrm{PO}_{2}\right]^{-}$represent trihexyl(tetradecyl)phosphonium and bis(2,4,4-trimethylpentyl) phosphinate ions, respectively, and subscripts PIM and aq refer to the PIM and aqueous phases, respectively.

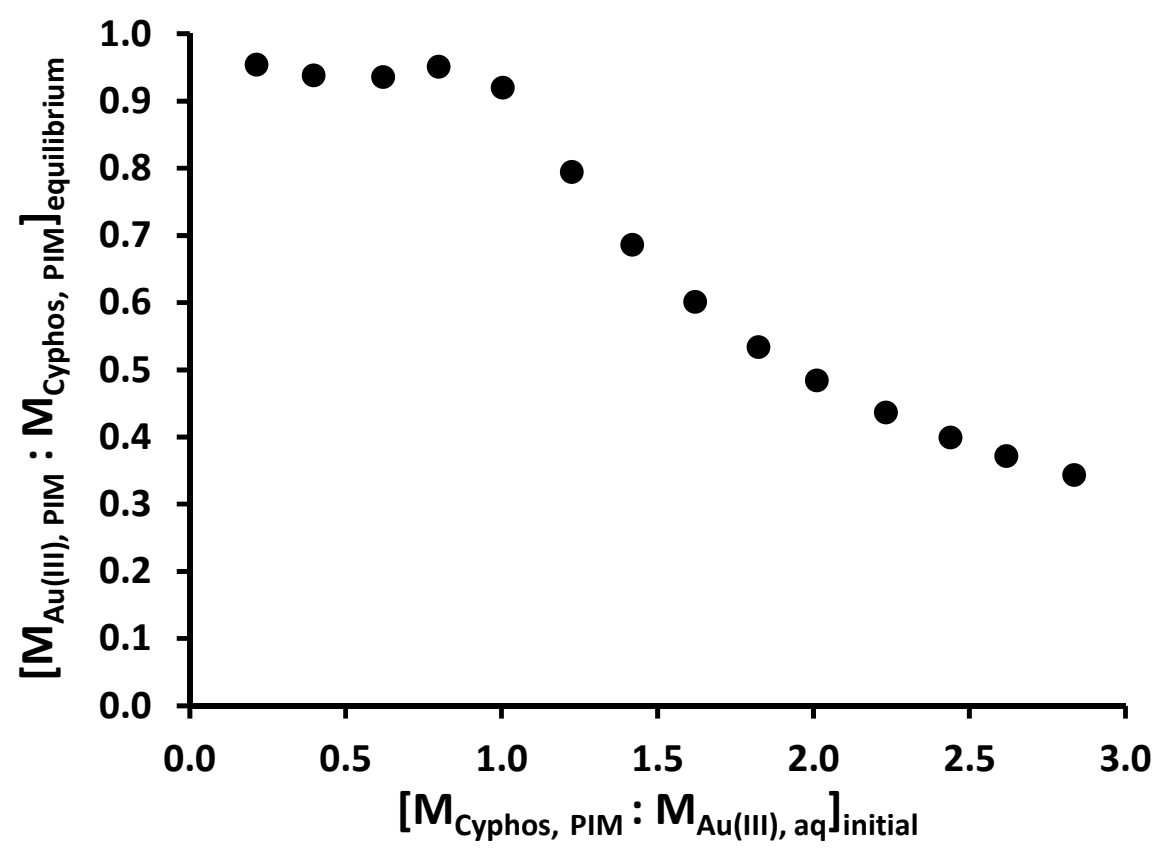

Figure 3. Determination of the stoichiometry of the $\mathrm{Au}(\mathrm{III})$-Cyphos ${ }^{\circledR}$ IL 104 adduct (Aqueous solution: $50 \mathrm{~mL}, 50 \mathrm{mg} \mathrm{L}{ }^{-1} \mathrm{Au}(\mathrm{III})$ in $2.5 \mathrm{~mol} \mathrm{~L}^{-1} \mathrm{HCl}$; membrane composition: $25 \mathrm{wt} \%$ Cyphos $^{\circledR}$ IL 104, $5 \mathrm{wt} \%$ 1-dodecanol and $70 \mathrm{wt} \%$ PVC; shaking rate: $150 \mathrm{rpm}$ ). Data points are the average of 3 extraction experiments with an average standard deviation of $0.14 \mathrm{mg} \mathrm{L}^{-1}$. Membranes of similar masses and sizes were used. 


\subsection{Au(III) Back-Extraction}

The back-extraction of $\mathrm{Au}(\mathrm{III})$ from the PIM was studied using $0.10 \mathrm{~mol} \mathrm{~L}^{-1}$ solutions of various back-extraction reagents and the results are summarized in Table 2. The results show that $\mathrm{Na}_{2} \mathrm{SO}_{3}$ is the most successful back-extraction reagent, giving almost complete back-extraction of $\mathrm{Au}(\mathrm{III})$ and providing a high initial flux. This can be explained by the reducing power of $\mathrm{Na}_{2} \mathrm{SO}_{3}$, which can reduce $\mathrm{Au}(\mathrm{III})$ to $\mathrm{Au}(\mathrm{I})$, which then forms the complex $\left[\mathrm{Au}\left(\mathrm{SO}_{3}\right)_{2}\right]^{3-}$ in the receiver solution. This triply-charged anion is less favorably re-extracted into the membrane due to its size and charge. A decrease in the $\mathrm{pH}$ of the receiver solution was also observed allowing the back-extraction process to be represented by Equation (2):

$$
\begin{gathered}
{[\mathrm{P}]^{+}\left[\mathrm{AuCl}_{4}\right]^{-} \mathrm{H}^{+}\left[\mathrm{PO}_{2}\right]_{(\mathrm{PIM})}^{-}+3 \mathrm{SO}_{3}{ }^{2-}{ }_{(\mathrm{aq})}+\mathrm{H}_{2} \mathrm{O}_{(\mathrm{aq})} \rightarrow} \\
{[\mathrm{P}]^{+}\left[\mathrm{PO}_{2}\right]^{-}{ }_{(\mathrm{PIM})}+\left[\mathrm{Au}\left(\mathrm{SO}_{3}\right)_{2}\right]^{3-}{ }_{(\mathrm{aq})}+3 \mathrm{H}^{+}{ }_{(\mathrm{aq})}+4 \mathrm{Cl}_{(\mathrm{aq})}^{-}+\mathrm{SO}_{4}{ }^{2-}{ }_{(\mathrm{aq})}}
\end{gathered}
$$

Table 2. The percentage back-extraction of $\mathrm{Au}(\mathrm{III})$ after $35 \mathrm{~h}$, and the initial back-extraction flux.

\begin{tabular}{ccc}
\hline Stripping reagent & \%Back-extraction & Initial flux $\left(\mathbf{m o l ~ m}^{-\mathbf{2}} \mathbf{~ s}^{\mathbf{1}}\right)$ \\
\hline $\mathrm{NaCl}$ & 13.7 & $1.26 \times 10^{-3}$ \\
$\mathrm{HCl}$ & 18.9 & $1.71 \times 10^{-3}$ \\
$\mathrm{KNO}_{3}$ & 13.8 & $7.64 \times 10^{-4}$ \\
$\mathrm{HNO}_{3}$ & 8.25 & $1.28 \times 10^{-3}$ \\
$\mathrm{KSCN}_{\mathrm{Na}} \mathrm{SO}_{3}$ & 8.71 & $7.85 \times 10^{-4}$ \\
$\mathrm{Na}_{2} \mathrm{~S}_{2} \mathrm{O}_{3}$ & 95.4 & $2.60 \times 10^{-3}$ \\
$\mathrm{Thiourea}$ & 68.2 & $2.63 \times 10^{-3}$ \\
$\mathrm{Na}_{2} \mathrm{SO}_{4}$ & 76.1 & $1.61 \times 10^{-3}$ \\
$\mathrm{H}_{2} \mathrm{SO}_{4}$ & 17.2 & $1.78 \times 10^{-3}$ \\
$\mathrm{NaClO}_{4}$ & 0.00 & 0.00 \\
$\mathrm{KBr}$ & 58.0 & $6.50 \times 10^{-4}$ \\
\hline
\end{tabular}

Note: Values are the average of 3 back-extraction experiments conducted for each back-extraction reagent with an average relative standard deviation of the $\%$ back-extraction of $1.67 \%$ and of the initial flux of $7.23 \times 10^{-5} \mathrm{~mol} \mathrm{~m}^{-2} \mathrm{~s}^{-1}$. Membranes of similar masses and sizes were used. The PIMs were loaded with $\mathrm{Au}(\mathrm{III})$ using $100 \mathrm{~mL}$ of a $100 \mathrm{mg} \mathrm{L}^{-1} \mathrm{Au}(\mathrm{III})$ solution in $2.5 \mathrm{~mol} \mathrm{~L}^{-1} \mathrm{HCl}$.

\subsection{Effect of $p H$ of the Receiver Solution}

Minsker et al. [11] have reported that PVC-based PIMs are prone to dehydrochlorination in solutions with high $\mathrm{pH}$ values, but are stable in weakly alkaline solutions [12]. Additionally, the speciation of sulfite is affected by the $\mathrm{pH}$ of the receiver solution [13]. The effect of the $\mathrm{pH}$ of the $\mathrm{Na}_{2} \mathrm{SO}_{3}$ solution on the back-extraction of $\mathrm{Au}(\mathrm{III})$ was studied in the region of $\mathrm{pH} 7-10$ by adjusting the $\mathrm{pH}$ using $\mathrm{HCl}$ or $\mathrm{NaOH}$ solutions, and the results are shown in Figure 4. The percentage backextraction of $\mathrm{Au}(\mathrm{III})$ at $\mathrm{pH} 7$ was lower than that at the higher $\mathrm{pH}$ values, and this could be explained by the lower mole fraction of the $\mathrm{SO}_{3}{ }^{2-}$ species present at $\mathrm{pH} 7(0.398)$ compared to $\mathrm{pH} 8(0.869), \mathrm{pH}$ 9 (0.985), and $\mathrm{pH} 10$ (0.998) [13]. The membranes exposed to $\mathrm{Na}_{2} \mathrm{SO}_{3}$ solutions at $\mathrm{pH} 9$ or 10 during the back-extraction process showed the presence of surface black spots, which were probably caused by localized dehydrochlorination of PVC in alkaline media. However, at $\mathrm{pH} 7$ and $\mathrm{pH} 8$, the 
membranes appeared visually to be unchanged. In addition, very small differences in both the rate and percentage back-extraction of $\mathrm{Au}(\mathrm{III})$ were observed at $\mathrm{pH} 8$ and higher. Therefore, $\mathrm{pH} 8$ was chosen as the optimal $\mathrm{pH}$ for $\mathrm{Au}(\mathrm{III})$ back-extraction without observing any effects of dehydrochlorination of PVC.

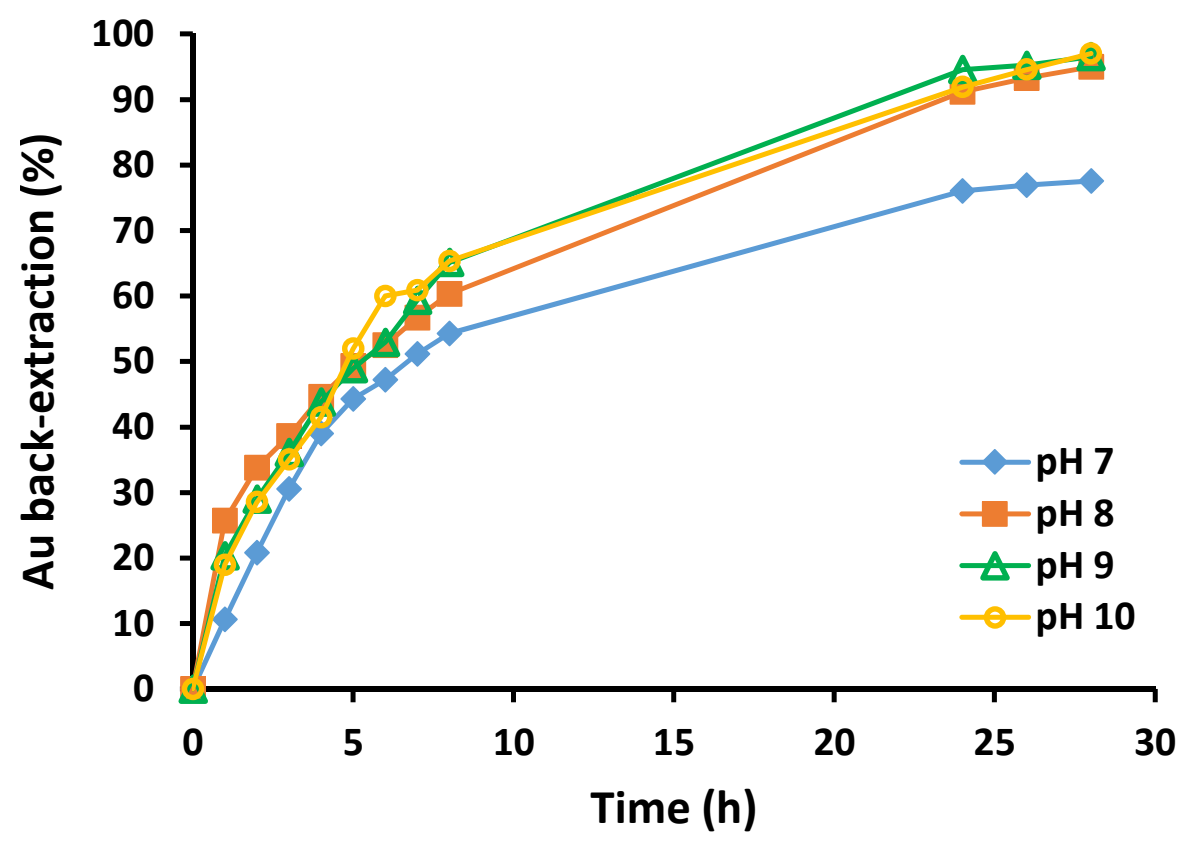

Figure 4. Percentage back-extraction of $\mathrm{Au}(\mathrm{III})$ with $\mathrm{Na}_{2} \mathrm{SO}_{3}$ vs. time for different $\mathrm{pH}$ values. Receiver solution volume and composition: $100 \mathrm{~mL}, 0.10 \mathrm{~mol} \mathrm{~L}^{-1} \mathrm{Na}_{2} \mathrm{SO}_{3}$; membrane mass and thickness: $60 \pm 3 \mathrm{mg}, 50 \pm 5 \mu \mathrm{m}$; membrane composition: $25 \mathrm{wt} \%$ Cyphos ${ }^{\circledR} \mathrm{IL} 104,5 \mathrm{wt} \%$ 1-dodecanol and $70 \mathrm{wt} \% \mathrm{PVC}$; shaking rate: $150 \mathrm{rpm}$. Data points are the average of 3 extraction experiments with an average standard deviation of $1.24 \mathrm{mg} \mathrm{L}^{-1}$. Membranes of similar masses and sizes were used.

\subsection{Effect of the $\mathrm{Na}_{2} \mathrm{SO}_{3}$ Concentration of the Receiver Solution}

The effect of the concentration of $\mathrm{Na}_{2} \mathrm{SO}_{3}$ on the back-extraction of $\mathrm{Au}(\mathrm{III})$ was studied using 0.05 , 0.10 and $1.0 \mathrm{~mol} \mathrm{~L}^{-1} \mathrm{Na}_{2} \mathrm{SO}_{3}$ receiver solutions at $\mathrm{pH} 8$ and the results are shown in Figure 5. The 0.05 mol L ${ }^{-1} \mathrm{Na}_{2} \mathrm{SO}_{3}$ solution was only able to back-extract close to $80 \%$ of the $\mathrm{Au}(\mathrm{III})$ present in the $\mathrm{Au}(\mathrm{III})$ loaded membrane, while both $0.10 \mathrm{~mol} \mathrm{~L}^{-1}$ and $1.0 \mathrm{~mol} \mathrm{~L}^{-1} \mathrm{Na}_{2} \mathrm{SO}_{3}$ solutions back-extracted $95 \%$ of the $\mathrm{Au}(\mathrm{III})$. Therefore, $0.10 \mathrm{~mol} \mathrm{~L}^{-1}$ was chosen as the preferred concentration of $\mathrm{Na}_{2} \mathrm{SO}_{3}$ in the receiver solution. 


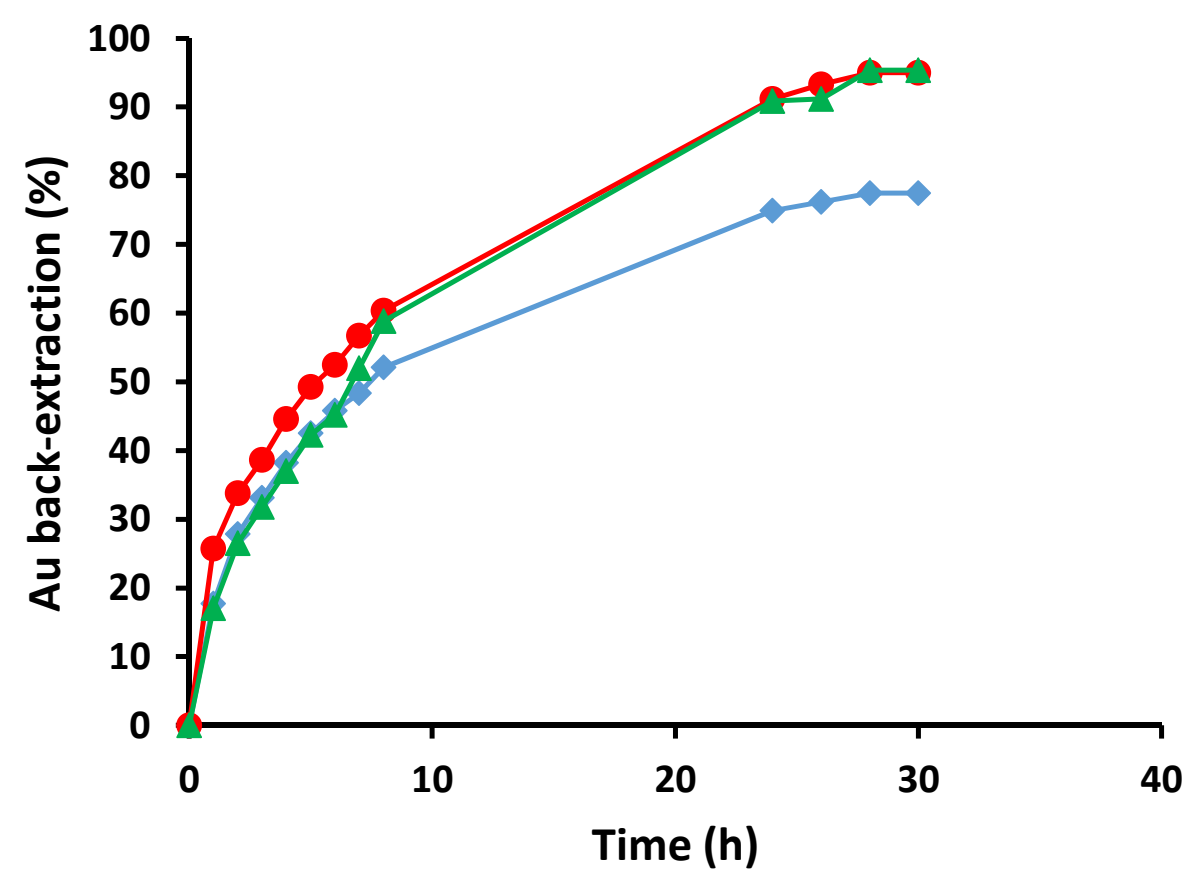

Figure 5. The percentage back-extraction of $\mathrm{Au}(\mathrm{III}) v s$. time for different concentrations of $\mathrm{Na}_{2} \mathrm{SO}_{3}\left(\diamond 0.05, \bullet 0.10\right.$ and $\Delta 1.0 \mathrm{~mol} \mathrm{~L}^{-1}$ ) (Receiver solution: $100 \mathrm{~mL}, \mathrm{pH} 8$; membrane mass and thickness: $60 \pm 3 \mathrm{mg}, 50 \pm 5 \mu \mathrm{m}$; membrane composition: $25 \mathrm{wt} \%$ Cyphos ${ }^{\circledR} \mathrm{IL}$ 104, $5 \mathrm{wt} \%$ 1-dodecanol and $70 \mathrm{wt} \%$ PVC; shaking rate: $150 \mathrm{rpm})$. Data points are the average of 3 extraction experiments with an average standard deviation of $1.30 \mathrm{mg} \mathrm{L}^{-1}$. Membranes of similar masses and sizes were used.

\subsection{Repeated Extraction/Back-Extraction Cycles}

Three consecutive extraction/back-extraction cycles were carried out with the same membrane. It was found that after the first cycle, the membrane lost its extraction ability. Additionally, after the first back-extraction, a significant amount of a white film formed on the surface of the PIM, which was verified by gas chromatography to contain 1-dodecanol. It appears that the loss of 1-dodecanol and the formation of the 1-dodecanol layer on the membrane surface are the reasons for the decline in the performance of the PIM.

\section{Experimental Section}

\subsection{Materials}

Cyphos ${ }^{\circledR}$ IL 104 (trihexyl(tetradecyl)phosphonium bis(2,4,4-trimethylpentyl) phosphinate) (Strem Chemicals Inc., min. 95\%) (Scheme 1) was used as received. High molecular weight powdered PVC ( $\mathrm{MM}=80,000$, Fluka) was used as the base polymer in the membrane preparation. Tetrahydrofuran (Chem-supply, Australia) was used as received. The following modifiers and plasticizers used in the PIM compositions were used as received: 1-dodecanol (Aldrich), 1-tetradecanol (Aldrich), 2-nitrophenol octyl ether (Fluka), dioctyl phthalate (Aldrich), and tri-2-ethyl-hexyl phosphate (Aldrich). Au(III) standards were prepared from a $1000 \mathrm{mg} \mathrm{L}^{-1} \mathrm{Au}$ standard (BDH Spectrosol) by dilution with hydrochloric acid (BDH AnalR). Au(III) solutions were prepared from chloroauric acid 
$\left(\mathrm{HAuCl}_{4}\right)$ (Aldrich) by dissolving it in hydrochloric acid solutions. In the $\mathrm{Au}(\mathrm{III})$ back-extraction studies, reagents were prepared by dissolving thiourea (BDH), sodium chloride (Chem-supply), potassium thiocyanate (BDH), sodium perchlorate (Chem-supply), sodium nitrate (Ajax), nitric acid (BDH AnalR), sulfuric acid (BDH AnalR), sodium thiosulfate (Ajax), sodium sulfite (BDH AnalR), sodium sulfate (BDH AnalR), or potassium bromide (Chem-supply) in deionized water (18 $\mathrm{M} \Omega \mathrm{cm}$, Millipore, Synergy 185, France). The $\mathrm{pH}$ of the receiver solutions was adjusted by using hydrochloric acid or sodium hydroxide (Chem-supply) solutions.

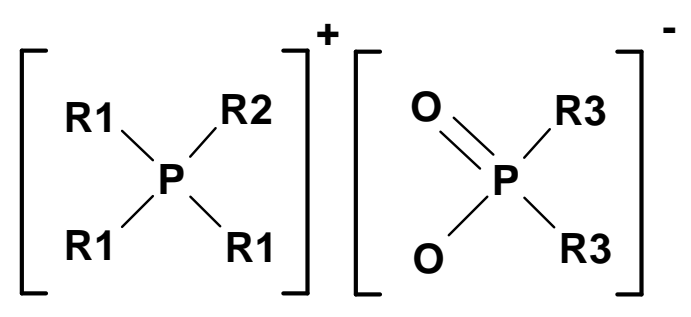

Scheme 1. Chemical structure of Cyphos ${ }^{\circledR}$ IL $104\left([\mathrm{P}]^{+}\left[\mathrm{PO}_{2}\right]^{-}\right)$where $\mathrm{R} 1=$ hexyl, $\mathrm{R} 2=$ tetradecyl and R3 = trimethylpentyl.

\subsection{Apparatus}

$\mathrm{Au}(\mathrm{III})$ concentrations were determined using atomic absorption spectrometry (AAS) (Hitachi Z-2000 Series Polarized Zeeman atomic absorption spectrophotometer, Japan). Au(III) extraction and back-extraction experiments were conducted using an orbital shaker (Platform Mixer OM6, Ratek). Optical microscopy and membrane thickness measurements were conducted with a Motic SMZ-140 stereo microscope (Motic, China) with 60× magnification in combination with a MoticCam 1000 microscope camera (Motic, China).

A gas chromatograph (Model GC 2010, Shimadzu) equipped with an EC-Wax capillary column $(30 \mathrm{~cm} \times 0.25 \mathrm{~mm} \times 0.25 \mu \mathrm{m}$, Alltech) and a flame ionization detector was used in the determination of 1-dodecanol.

\subsection{Membrane Preparation}

Cyphos $^{\circledR}$ IL 104, PVC and a plasticizer or modifier (when required), with a total mass of $400 \mathrm{mg}$, were dissolved in a small volume $(8-10 \mathrm{~mL})$ of THF. The solution was poured into a glass ring with a diameter of $7.5 \mathrm{~cm}$, positioned on a flat glass plate. The mixture was covered with a filter paper and a watch glass to allow slow evaporation of the solvent over a $24 \mathrm{~h}$ period leaving a transparent and flexible circular membrane. The membrane was removed from the glass plate and cut to size (mass: $60 \pm 3 \mathrm{mg}$, diameter: $3.5 \mathrm{~cm}$, thickness: $50 \pm 5 \mu \mathrm{m})$.

\subsection{Membrane Extraction and Back-Extraction Experiments}

In the extraction experiments membranes were immersed in $100 \mathrm{~mL}$ of $100 \mathrm{mg} \mathrm{L}^{-1} \mathrm{Au}$ (III) solutions containing $2.5 \mathrm{~mol} \mathrm{~L}^{-1} \mathrm{HCl}$ in glass jars which were shaken on an orbital shaker at $150 \mathrm{rpm}$. Samples of the $\mathrm{Au}(\mathrm{III})$ solution $(0.2 \mathrm{~mL})$ were removed at predetermined time intervals throughout the 
course of the experiments. The samples were diluted to $4 \mathrm{~mL}$ with deionized water and the $\mathrm{Au}(\mathrm{III})$ concentration was determined by AAS.

Membranes containing $\mathrm{Au}(\mathrm{III})$ were back-extracted by immersing them in receiver solutions $(100 \mathrm{~mL})$ containing a stripping reagent, which were shaken on an orbital shaker at $150 \mathrm{rpm}$. The back-extraction process was monitored by continuously sampling the solutions $(0.2 \mathrm{~mL})$ at predetermined time intervals as in the extraction experiments.

\subsection{Stoichiometry of the Au(III)/Cyphos ${ }^{\circledR}$ IL 104 Adduct}

The stoichiometry of the extracted adduct was determined by using a variation of the method described by St. John et al. [10]. Individual PIM segments of composition $25 \mathrm{wt} \%$ Cyphos ${ }^{\circledR}$ IL 104, $5 \mathrm{wt} \%$ 1-dodecanol and $70 \mathrm{wt} \% \mathrm{PVC}$ with varying masses were immersed in individual jars containing $50 \mathrm{~mL}$ of a solution containing $50 \mathrm{mg} \mathrm{L}^{-1} \mathrm{Au}(\mathrm{III})$ and $2.5 \mathrm{~mol} \mathrm{~L}^{-1} \mathrm{HCl}$. The masses of the membrane segments were varied between 8 and $125 \mathrm{mg}$, which allowed the variation of the mole ratio of Cyphos $^{\circledR}$ IL 104 in the PIM to Au(III) in the solution between 0.20:1 to 3.2:1. The jars were agitated on an orbital shaker at $150 \mathrm{rpm}$ for 5 days to allow the systems to reach equilibrium and the $\mathrm{Au}$ (III) concentration in each jar was determined by AAS.

\subsection{Initial Flux Calculations}

The initial flux $\left(J_{0}, \mathrm{~mol} \mathrm{~m}^{-2} \mathrm{~s}^{-1}\right)$ was calculated according to Fick's first law, by fitting the transient $\mathrm{Au}(\mathrm{III})$ concentration with an exponential decay function $\left(\bar{C}=a_{1}+a_{2} e^{-a_{3} t}\right)$ the first derivative of which $\left((d \bar{C} / d t)_{t=0}\right)$ was used to calculate $J_{0}$ according to Equation (3):

$$
J_{0}=\frac{V}{S} \cdot\left[\frac{d C}{d t}\right]_{t=0}
$$

where $V$ is the volume of the solution $\left(\mathrm{m}^{3}\right), S$ is the surface area of the membrane $\left(\mathrm{m}^{2}\right), \mathrm{C}$ is the concentration of $\mathrm{Au}(\mathrm{III})\left(\mathrm{mol} \mathrm{m}^{-3}\right)$, and $t$ is time (s).

\section{Conclusions}

This study examined a number of PIMs composed of Cyphos ${ }^{\circledR}$ IL 104 as the extractant for Au(III) with PVC as the base polymer. Some of the PIMs also incorporated a plasticizer or modifier. Only PIMs prepared without a plasticizer or modifier or with 1-dodecanol as the modifier were homogeneous, transparent and flexible. The other membranes had oily surfaces, which indicated incompatibility of the components in the PIMs.

The membrane with a composition of $25 \mathrm{wt} \%$ Cyphos $^{\circledR}$ IL 104, $5 \mathrm{wt} \%$ 1-dodecanol and $70 \% \mathrm{wt}$ PVC showed the fastest rate of extraction and highest amount of $\mathrm{Au}(\mathrm{III})$ extracted from solutions with a $\mathrm{HCl}$ concentration of $2.5 \mathrm{~mol} \mathrm{~L}^{-1}$. The stoichiometry of the adduct formed between Cyphos ${ }^{\circledR}$ IL 104 and $\mathrm{Au}(\mathrm{III})$ in the PIM was determined to be $[\mathrm{P}]^{+}\left[\mathrm{AuCl}_{4}\right]^{-} \mathrm{H}^{+}\left[\mathrm{PO}_{2}\right]^{-}$, where $[\mathrm{P}]^{+}$and $\left[\mathrm{PO}_{2}\right]^{-}$represent trihexyl(tetradecyl)phosphonium and bis(2,4,4-trimethylpentyl) phosphinate ions, respectively.

An extensive study of a number of back-extracting reagents for the back-extraction of $\mathrm{Au}$ (III) from $\mathrm{Au}$ (III) loaded PIMs found that the solution containing $0.10 \mathrm{~mol} \mathrm{~L}^{-1} \mathrm{Na}_{2} \mathrm{SO}_{3}$ at $\mathrm{pH} 8$ gave the highest percentage back-extraction and the highest initial back-extraction flux. The mechanism for back-extraction 
is suggested to involve reduction of $\mathrm{Au}(\mathrm{III})$ to $\mathrm{Au}(\mathrm{I})$, with the formation of the complex $\left[\mathrm{Au}\left(\mathrm{SO}_{3}\right)_{2}\right]^{3-}$ in the receiver aqueous solution.

The loss of 1-dodecanol from the PIM after one extraction/back-extraction cycle and the formation of the 1-dodecanol layer on the membrane surface resulted in deterioration of the performance of the PIM. This characteristic inhibits the use of the PIM in a continuous transport system unless another modifier can be found to eliminate the problem. Nevertheless, the newly developed PIM could be potentially suitable for a single use process for efficiently recovering $\mathrm{Au}(\mathrm{III})$ from diluted aqua regia solutions of electronic scrap or recycled jewelry. The high price of gold justifies financially this approach.

\section{Acknowledgements}

Ya Ya Nutchapurida Bonggotgetsakul is grateful to the University of Melbourne for receiving the Albert Shimmins Postgraduate Writing-up Award.

\section{Author Contributions}

Ya Ya Nutchapurida Bonggotgetsakul conducted the experimental work as a PhD student under the supervision of Spas D. Kolev and Robert W. Cattrall. All three authors contributed to the writing of the manuscript.

\section{Conflicts of Interest}

The authors declare no conflicts of interest.

\section{References}

1. Argiropoulos, G.; Cattrall, R.W.; Hamilton, I.; Kolev, S.D.; Paimin, R. The study of a membrane for extracting gold(III) from hydrochloric acid solutions. J. Membr. Sci. 1998, 138, 279-295.

2. Miguel, E.R.D.; Garduno-Garcia, A.V.; Aguilar, J.C.; de Gyves, J. Gold(III) transport through polymer inclusion membranes: Efficiency factors and pertraction mechanism using Kelex 100 as carrier. Ind. Eng. Chem. Res. 2007, 46, 2861-2869.

3. Fontas, C.; Antico, E.; Vocanson, F.; Lamartine, R.; Seta, P. Efficient thiacalix[4]arenes for the extraction and separation of $\mathrm{Au}(\mathrm{III}), \mathrm{Pd}(\mathrm{II})$ and $\mathrm{Pt}(\mathrm{IV})$ metal ions from acidic media incorporated in membranes and solid phases. Sep. Purif. Technol. 2007, 54, 322-328.

4. Nunez, M.E.; de San Miguel, E.R.; Mercader-Trejo, F.; Aguilar, J.C.; de Gyves, J. Selective omega-thiocaprolactam-based recovery of $\mathrm{Au}(\mathrm{III})$ from chloride media in solvent extraction and polymer inclusion membrane systems. Sep. Purif. Technol. 2006, 51, 57-63.

5. Bonggotgetsakul, Y.Y.N.; Ashokkumar, M.; Cattrall, R.W.; Kolev, S.D. The use of sonication to increase extraction rate in polymer inclusion membranes. An application to the extraction of gold(III). J. Membr. Sci. 2010, 365, 242-247.

6. Pereira, N.; St John, A.; Cattrall, R.W.; Perera, J.M.; Kolev, S.D. Influence of the composition of polymer inclusion membranes on their homogeneity and flexibility. Desalination 2009, 236, $327-333$. 
7. Almeida, M.; Cattrall, R.W.; Kolev, S.D. Recent trends in extraction and transport of metal ions using polymer inclusion membranes (PIMs). J. Membr. Sci. 2012, 415, 9-23.

8. Nghiem, L.D.; Mornane, P.; Potter, I.D.; Perera, J.M.; Cattrall, R.W.; Kolev, S.D. Extraction and transport of metal ions and small organic compounds using polymer inclusion membranes (PIMs). J. Membr. Sci. 2006, 281, 7-41.

9. Guo, L.; Liu, Y.H.; Zhang, C.; Chen, J. Preparation of PVDF-based polymer inclusion membrane using ionic liquid plasticizer and Cyphos IL 104 carrier for $\mathrm{Cr}(\mathrm{VI})$ transport. J. Membr. Sci. 2011, 372, 314-321.

10. St John, A.M.; Cattrall, R.W.; Kolev, S.D. Extraction of uranium(VI) from sulfate solutions using a polymer inclusion membrane containing di-(2-ethylhexyl)phosphoric acid. J. Membr. Sci. 2010, 364, 354-361.

11. Minsker, K.S.; Kulish, E.I.; Zaikov, G.E. Kinetic-parameters of PVC dehydrochlorination in solutions. Intl. J. Polymeric Mater. 1994, 24, 107-110.

12. Cho, Y.; Xu, C.L.; Cattrall, R.W.; Kolev, S.D. A polymer inclusion membrane for extracting thiocyanate from weakly alkaline solutions. J. Membr. Sci. 2011, 367, 85-90.

13. Gutz, I.G.R. CurTiPot-pH and Acid-Base Titration Curves: Analysis and Simulation freeware, Version 4.2.2, September 2015; software for MS-Excel.

(C) 2015 by the authors; licensee MDPI, Basel, Switzerland. This article is an open access article distributed under the terms and conditions of the Creative Commons Attribution license (http://creativecommons.org/licenses/by/4.0/). 